\title{
PECULIARITIES OF HEALTHCARE SPECIALISTS' COMMUNICATIVE COMPETENCE IN ENGLISH AS A FOREIGN LANGUAGE
}

\author{
Olga Pašinska \\ The Red Cross Medical College of Riga Stradiņš University, Latvia
}

\begin{abstract}
Healthcare specialists are expected to possess competences essential for a successful fulfilment of their duties. Although specialists' practical competences enabling them to deal with a wide range of health conditions are the key ones, communicative competence, implying an ability to use a target language "accurately, appropriately, and flexibly" (Yule, 2010, p.194), has also had an immense impact on the accomplishment of professional duties (World Health Organisation, 2005). It follows that apart from giving opportunities to acquire knowledge about medicine and practical skills, medical education institutions are expected to teach $21^{\text {st }}$ century students to communicate effectively using various linguistic tools applicable in their professional context (Zethsen and Askehave, 2006). The present article aims to elucidate the peculiarities of communicative competence that practising or future healthcare providers should possess in order to demonstrate how it enables them to accomplish their responsibilities by communicating with patients and, thus, provide them with qualitative care or treatment in a foreign language, specifically English as a foreign language. With the aim to reach the goal, a scientific literature review was conducted. The theoretical implications were supported by the examples of medical encounters; in the given encounters, the use of the selected language aspects and participants' non-verbal cues were interpreted.
\end{abstract}

Keywords: communicative competence, healthcare specialist, EFL.

\section{Introduction}

The description of medical language, more specifically, its application in professional discourse, is one of the oldest and most prominent topics in applied linguistics (Barton, 2005). The exploration of the peculiarities of medical language, the nature of health communication as well as related language competences has both theoretical and practical values. Its doctrinal value lies in the development of the theoretical basis that would provide an insight into "the institutional interaction, relationships as created and reflected by discourse, and specialized sequences within the interaction of medical encounters” (ibid.). The practical value, in its turn, manifests itself in the provision of data on the basis of which the methodologies and teaching materials aimed at the enhancement of medical specialists' communication skills could be developed (ibid.). 
Pašinska, 2021. Peculiarities of Healthcare Specialists' Communicative Competence in English as a Foreign Language

Despite the fact that medical language and its peculiarities in communication are widely explored (e.g. Roter \& McNeilis, 2003; Heritage \& Maynard, 2006; Miller et al., 2016), there are few studies that focus on the language user, specifically language competences a practising or future professional should possess in order to communicate with patients in healthcare institutions.

Therefore, the goal of this article is to provide an account of the peculiarities of communicative competence, including the related competences, a caregiver is expected to have, supporting them by the examples of medical encounters. The focus of the paper is not only one's native language, but also English as a foreign language which has gradually become an international language in the field of public healthcare due to worldwide globalisation. In order to reach the goal, the following research questions have been formulated: 1) how has the notion of communicative competence evolved? 2) how are communicative competence and its related competences manifested in the interaction between a healthcare provider and a patient? 3) what is the role of a healthcare provider as a possessor of a communicative competence in communication with a patient? 4) what are the factors that influence the realisation of communication?

\section{Methodology}

This study is a part of a larger research project which is concerned with the elaboration of teaching materials aimed at medical students' communication skill enhancement in English as a foreign language. In order to develop qualitative materials that pursue the above-stated aim as well as guidelines for their effective application, first, it is essential to explore the nature of communicative competence and its importance for healthcare providers. This served as an impetus for the present research.

The goal set at the beginning of the research determined the methodology, that is, a literature review and interpretation of linguistic and paralinguistic sources in medical encounters. A scientific literature review enabled me to conduct "a critical examination of existing research" (Bryman, 2012, p.14) devoted to communicative competence and other competences related to it. A pedagogical framework of communicative competence developed by CelceMurcia, M., Dornyei, Z. \& Thurrell, S. (1995) was put in the main focus of the present research. First, the development of the term of communicative competence in the field of applied linguistics was traced; then, its peculiarities in the relation to the healthcare field were identified; after that, a communication participant's role in medical encounters was established; finally, factors influencing effective communication were viewed.

Both linguistic and paralinguistic sources were interpreted in the chosen examples of medical encounters to support theoretical findings. The use of the 
selected linguistic sources was illustrated on the examples of the dialogues extracted from previous research and various English for Medical Purposes books. The use of non-verbal cues, which are an important source of information in terms of communication, were analysed in the film fragments that depict interaction between a healthcare provider and a patient or his/her relative.

\section{Manifestation of the Peculiarities of Communicative Competences in Medical Encounters}

This section includes a description of the evolution of communicative competence, characteristics of communicative competence as well as other competences that build up the communicative one. They are illuminated in the context of healthcare.

In the mid-1990s the role of communicative competence, which is defined as an ability to communicate and understand utterances across linguistic, situational, social and cultural boundaries, has been actively discussed in the context of applied linguistics (Celce-Murcia, 2007). Since then, the interest in the issue has not decreased. In 1995, Celce-Murcia, together with Dörnyei and Thurrell, offered a pedagogical framework for communicative competence (see figure 1) (1995, p.10). Their model is represented by a circle within a pyramid, in the centre of which there is discourse competence. The three points that surround the circle are linguistic, sociocultural and actional competences. The triangle, in its turn, is surrounded by another circle which denotes strategic competence. All the above-mentioned competences build up the communicative one.

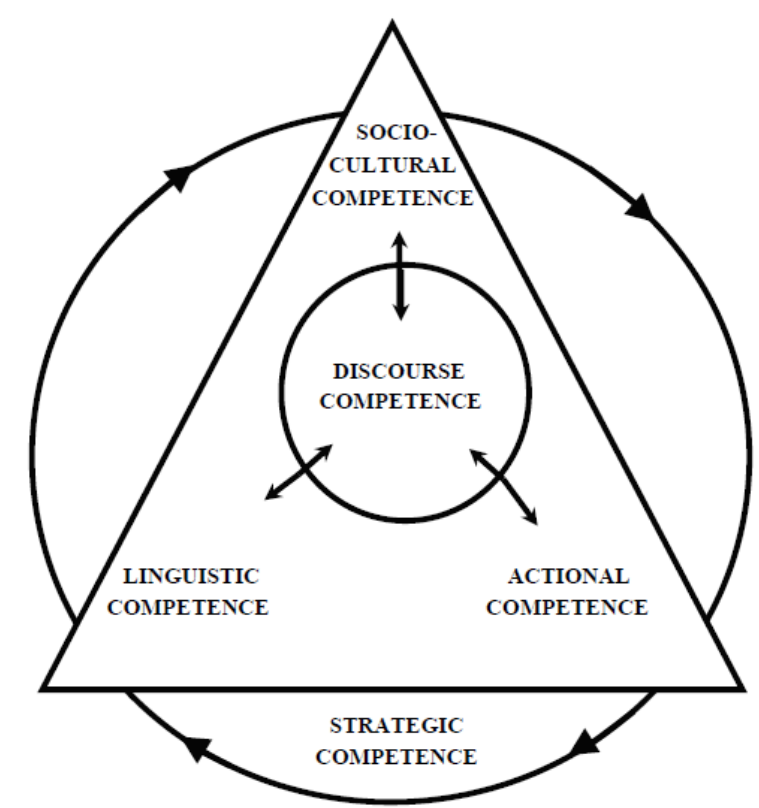

Figure 1 Representation of communicative competence (Celce-Murcia, Dörnyei and Thurrell, 1995, p.10) 
Pašinska, 2021. Peculiarities of Healthcare Specialists' Communicative Competence in English as a Foreign Language

The evolution of communicative competence began with the linguistic one. The concept of linguistic competence is considered to be one of the most controversial concepts in the scientific field of applied linguistics. The notion was first defined by Noam Chomsky as "the speaker-hearer's knowledge of [...] language" enabling him/her to produce grammatically correct sentences and utterances as well as recognize their different types (1965, p.4). The American linguist claims that linguistic knowledge is the unconscious mental knowledge the ideal native speaker has at his/her disposal, and it is not affected by any situational, social and cultural factors during a specific linguistic performance (Chomsky, 1965). In this way, linguistic competence implies that a speaker, including a medical practitioner, is expected to possess phonological, lexical, morphological and syntactic knowledge in order to lead a conversation successfully. A healthcare provider is expected to know the following syntactic knowledge to achieve his/her professional goals, for example, imperatives for giving instructions, modal verbs can and may for informing about side effects of drugs, different types of questions for eliciting specific information from a patient (McCarter, 2013, 2014).

Chomsky's notion of linguistic competence was challenged by the hypothesis of Dell Hymes (1972) and Sandra Savignon (1972) who argued that the knowledge of grammatical rules and an ability to apply it are not sufficient for effective communication, due to the fact that communicative practices are socially and culturally situated. Thus, Chomsky's perspective on the notion competence was not considered relevant to real-life communication (Hymes, 1972). It served as an impetus to introduce the notion of communication competence. Its idea was that "linguistic competence must adapt itself to the total informational input, both linguistic and paralinguistic" (Savignon, 1972, p.8). Thus, a communication participant should have not only the knowledge of a language as a code, but be aware of situational, social and cultural aspects of specific discourse. These aspects determine the language, namely, the choice of linguistic macro- and microstructures, lexemes and language strategies to which a speaker appeals to achieve his/her goals, including the professional ones. Three salient characteristics of medical communication in terms of language use, taking into account the above-mentioned aspects, is simplicity, provision of a large number of details and/or explanations, as well as extensive use of grammatical structures aiming at politeness.

The first peculiarity being discussed is simplicity. Simplicity means that a healthcare specialist should use the language that is maximally understandable for a patient, excluding professional terminology (Travaline et al., 2005). If medical terms cannot be avoided, their explanations should be provided (ibid.). This may be illustrated on the examples of the cases in which a healthcare specialist (CCS in all further dialogues) informs a patient ( $\mathrm{P}$ - in all further dialogues) or patient's 
relative about the 1) disease that his/her patient has, 2) investigation methods he/she requires and 3) treatment he/she will undergo:

1) CCS: As I though, you are a little bit anaemic.

$\mathrm{P}$ : Is that bad?

CCS: No, not necessarily. It just means that your red blood cell count is a little on the low side (...). (Grice, 2011, p.129)

2) CCS: Well, what we are going to do is have a look at your gullet and your stomach to see what's going on there.

P: OK. (McCarter, 2013, p.134)

3) CCS: (...) What we're going to need to do, with your consent, is to give your husband something to help get rid of any blood clots. [...]

P: OK. (McCarter, 2014, p.134)

The first example demonstrates that when the professional mentions a medical term anaemia, an explanation of this term follows, because the patient is not familiar with it, since a question about it is raised. It is also noteworthy that when describing analysis results, that is, a red blood cell count, the professional uses such collocation as to be on the low side, instead of to be decreased or to be diminished that are the terms with which foreign patients, especially the ones who have low a level of English proficiency, might not be familiar.

As concerns the second excerpt, it should be noticed that the healthcare provider does not mention such professional term as gastroscopy; conversely, he/she explains the procedure in as simple language as possible, not forgetting to mention what the aim of this procedure is. As a result, there are no questions raised from a patient's side, which was the case in the first dialogue.

As concerns the third dialogue, the medical specialist uses the same explanation tactic as the professional in the second dialogue. Respectively, he/she omits the use of a professional term thrombolysis in order to explain the procedure his/her patient is going to undergo. Instead, he explains the procedure in the language understandable for the patient to make himself/herself explicit; it is done intentionally with the aim not to cause confusion.

The second peculiarity of oral communication in medical appointments is provision of the details about a patient's condition, medical examination and treatment (Travaline et al., 2005). For example, when discussing the course of medical examination or treatment, a healthcare specialist is to explain its each step as in the following examples:

1) CCS: I think that a CT scan should be done. [...] The CT scan is a hightech kind of an X-ray. It shows important details of your brain. It does not hurt and it is not dangerous. During the study you will be lying on your back on a stretcher. The technician will advance your head into a narrow tunnel for about 8 minutes. There is nothing to be worried about. There will be enough breathing space around your head. You will be able to speak to the technician by a 
Pašinska, 2021. Peculiarities of Healthcare Specialists' Communicative Competence in English as a Foreign Language

microphone in the CT tunnel. The tunnel serves to bring electronic imaging machinery close to your head. Have you ever been afraid of tunnels in your life before? (Gross \& Baumgart, 2006, p.156)

2) CCS: Acne's nothing to do with poor hygiene, but if you wash twice a day and then put on a moisturizer like aqueous cream, that will help.

P.: Aque...

CCS: Aqueous cream. It's this. It comes in tubs like this. And cream here. I'm going to give you some cream - benzoyl peroxide - to put on twice a day and this antibiotic cream. [...] Now, I must point out that these can take weeks to work, so you need to be patient. (McCarter, 2014, p.132)

The excerpts from the dialogues above show that the caregivers provide a wide range of information about the medical examination and treatment their patients are going to experience, namely, gastroscopy and acne treatment. The aim of giving such detailed descriptions is to make patients fully aware of the forthcoming procedures and, consequently, prepare them for these experiences both physically and emotionally.

In the first conversation the professional informs which type of investigation is needed, what its essence is and the benefits of exactly this type of investigation. The physician also gives information about working principles of a computed tomography (CT) scanner. In addition, he/she mentions how safe CT is, since this is what patients usually enquire about any type of procedure. The specialist also describes what will be the actions of the patient throughout the session, which is significant, since adherence to doctor's instructions or their violation might influence the outcomes of investigation. It is also noteworthy that the specialist asks about patient's fear of closed tunnels. This may be required either to understand which else type of information is needed to be provided to the patient, or warning that uncomfortable feelings might appear due to enclosed space.

In the second interaction the physician provides the following details. He/she gives the reason why this type of treatment is needed and names the specific title of medication that is required, including its form. The specialist also tells the patient how to use it and how often to use it. Moreover he/she does not ignore mentioning treatment duration and an anticipated outcome.

The third peculiarity of health communication in terms of language use is active exploitation of specific grammatical structures to achieve polite utterances (Wodak, 2006). When a healthcare provider gives his/her patient instructions, the use of directives, for example, "Open your mouth", should be avoided, because it may often sound harsh and impolite (McCarter, 2013, p.25). For this reason, it is recommended to refer to such structures as “...for me, please”, "Can/could you (just) + infinitive (without 'to')”, “...if you can/could” and 'I'd like you + infinitive', indirect questions to make requests and instructions sound polite 
(ibid.). The following examples from medical encounters demonstrate the use of the above-mentioned and similar structures:

1) CCS: Could you just bend your head forward for me, please? (McCarter, 2013, p.25)

2) CCS: [...] your oncologist thought it would be good to come and see me and I just wondered why you were coming to see me.

P: uhm (.) well basically it's because my hip's still giving me pain [...]. (Finlay \& Sanargi, 2006, p.670)

As demonstrated in the first example, during a physical examination of the patient the healthcare provider uses an interrogative with could to form a request, instead of using an imperative form, namely, "bend your head forward" which would sound harsh at some extent. The phrase at the end of the sentence, "for me, please”, in its turn, is used to soften the request.

As concerns the second example, an indirect question, namely, "I just wondered why..." was chosen as a form for the same purpose - formation of a polite request. It was done intentionally, since the direct question, specifically, "Why are you coming to see me?" would sound unprofessional in the medical settings; it is possible that the patient could perceive it as specialist's irritation or unwillingness to admit him/her as a patient.

The next competence under consideration in this section is the discourse one; it implies "the selection, sequencing, and arrangement of words, structures, sentences and utterances to achieve a unified spoken [...] text" (Celce-Murcia et al., 1995, p.13). Celce-Murcia puts emphasis on the significance of this competence as a central element of communicative competence, since it unites other competences in order to create an integral text fitting specific social and socio-cultural settings $(2007$, p.44, 46). This aim can be achieved with the help of cohesion, including such elements as conjunctions and lexical chains; coherence which deals with textual macrostructural elements; deixis that includes deictic pronouns, spatial, temporal and textual references; generic structures that consist of ordering structural elements; and conversational structures that focus on a turntaking system in oral conversations (ibid., p.14-15). According to Hatch's discourse theory (1992), following scripts enables interactants to communicate in certain situations flawlessly (Hatch, 1992, p.107). It implies that the scripts of conversations related to the medical field should be acquired by practising or future professionals during their studies. The scholar enumerates script components, including goals, actors, props and actions (1992, p.85-86). In the medical discourse script components depend on the medical subfield, functions, conversation participants and interlocutor's goals. In communication between a physician and a patient, the healthcare provider's goals might be as follows: to reformulate pain description, give instructions, summarise a health situation, describe interventions, apologise to a patient, show empathy, inform a patient of 
Pašinska, 2021. Peculiarities of Healthcare Specialists' Communicative Competence in English as a Foreign Language

bad news, manage patient's anger and other actions related to his/her profession (Isaacs, Laurier, Turner, \& Segalowitz, 2011, p.565). As concerns the roles, the roles of a specific healthcare provider, for example, a nurse, and a patient can be identified in the field of healthcare. Props, depending on the situation, may vary from simple medical equipment, for example, a thermometer and sphygmomanometer, to sophisticated machines, for example, haemodialysis and MRI machines. The last component, that is, an action, implies the activities that accompany a conversation, for example, a nurse taking notes onto a patient medical history form while interviewing him/her and a general practitioner taking a stethoscope and placing it on the patient's chest while asking about the pain in the chest.

Describing their framework of communicative competence, Celce-Murcia et al. emphasize the role of sociocultural competence, which denotes 'the speaker's knowledge of how to express messages appropriately within the overall social and cultural context of communication (1995, p.23). In health communication, the possession of this competence is especially significant when either a caregiver, or a patient does not speak his/her native language. The significance of this competence was also confirmed by a recent study in which its author claimed that the questions of professional communication should be more thoroughly investigated from sociological and cultural angles (Ponomarenko et al., 2020, p.4). A healthcare provider is expected to possess an ability to use a language "at an appropriate level of formality for the situation, observing social as well as cultural norms in respect of conventions", adapting also his/her body language (Coelho, 2004, p.109). Celce-Murcia et al. describe several sociocultural variables that a communication participant is supposed to bear in mind when interacting. They include:

- social contextual factors: the participants' age, gender, status, social distance and their relations to each other: power and affect;

- stylistic appropriateness: politeness strategies, a sense of genres and registers;

- cultural factors: background knowledge of the target language group, major dialects/regional differences, and cross-cultural awareness. (1995, p.23-24)

The style of communication may vary depending on socio-contextual factors, for example, patient's gender and social distance. In this way, a physician's style of communication differs when talking to children, adults or the elderly. A conversation with a child is typically started referring to his/her emotions, for instance, by asking about fears (Levetown, 2008, p.e1441), specifically fear of pain. Then a medical professional is expected to relieve child's anxiety and eradicate his/her fear, and only then move to examination (ibid.). 
Stylistic appropriateness, in its turn, manifests itself in physician's formulation of utterances. For example, a physician is meant to use some introductory sentences when informing negative news to a patient to sound empathetic, for example, "I realise this probably comes as a shock to you" or "It is not easy saying that, but there is a chance that your wife may not get any better" (Lloyd \& Bor, 2009, p.67, 72).

Culture of interactant participants is another factor that defines the nature of communication. When communicating with a foreign patient, a healthcare provider should be aware of the cultural norms of his/her patient (Mutha, Allen, \& Welch, 2002). For example, a woman of Islamic religion will expect to be given a physical examination by a female physician, since a male's touch is highly undesirable in her religion (Chamsi-Pasha \& Ali Albar, 2016, p.123).

The next competence under consideration is strategic competence, which denotes "knowledge of communication strategies and how to use them" (CelceMurcia et al., 2007, p.26). According to Celce-Murcia et al., communication strategies include avoidance strategies which involve "tailoring one's message" by replacing it or avoiding some specific topics, and abandoning it (1995, p.27); the achievement strategies which imply "manipulating available language to reach a communicative goal" (ibid.); stalling or time gaining strategies which denote the use of "filters, hesitation devices, gambits as well as repetitions" (ibid.); self-monitoring strategies that consist of self-repair and rephrasing (ibid.); and interactional strategies that are regarded to be the ones that are used to appeal for help from an interlocutor's side, for example, confirmation check (ibid.). The following examples are given to demonstrate the application of several strategies:

1) CCS: Mustapha, isn't it?

P: Yes, that's right.

CCS: So what happened to you? (...) (Grice, 2011, p.126)

2) CCS (intern): And he shouldn't eat sugar, right?

CCS: Well, no, it's not true that diabetic shouldn't eat sweet things. Actually, what's important is balance. (ibid., p.128)

The first example demonstrates the application of an interactional strategy, the goal of which is confirmation check. This is highly important in the clinical settings, since checking patient's identity is one of the medical staff studies. In this specific case, the use of the word "right" at the end of a closed-ended question would imply an affirmative or negative response.

The second example, in its turn, shows the use of time-gaining devices, such as "well" and "actually". They are typically used to save time that might be needed for formulation of a sentence or recalling what other information is needed to be introduced to a patient or colleague. In addition, the use time-gaining words and phrases in physician's speech might be beneficial for patients, since it gives them more time to process information which is new for them. 
Pašinska, 2021. Peculiarities of Healthcare Specialists' Communicative Competence in English as a Foreign Language

The last but not the least important competence in the focus of the present study is actional competence, which was firstly introduced by Celce-Murcia et al. in 1995. Actional competence is defined as "competence in conveying and understanding a communicative intent, that is, matching actional intent with linguistic form" (ibid., p.17). Special attention should be devoted to the development of non-native speaker's actional competence, since non-native speaker's actional behaviours might not be always contextually appropriate, since their knowledge of linguistic sources are distinct from their knowledge of sociocultural norms (Celce-Murcia et al., 1995, p.19). For this reason, they might often be unaware actional intents of specific linguistic sources. As a result, it may cause misunderstanding between interlocutors. As to the types of actional intentions, they include the ones that refer to interpersonal exchange, information exchange, opinion and feeling exchange, suasion and discussion of future plans (ibid., p.22). The following examples demonstrate some of the actional intents of healthcare specialists and linguistic sources they used to achieve their intents:

1) CCS: As I though, you are a little bit anaemic.

$\mathrm{P}$ : Is that bad?

CCS: No, not necessarily. It just means that your red blood cell count is a little on the low side. A normal count is about 4.2 to 5.4 million red blood cells per microlitre of blood, and yours was 3.9.

P: Oh dear - what does that mean? (...). (Grice, 2011, p.128)

2) CCS: Acne's nothing to do with poor hygiene, but if you wash twice a day and then put on a moisturizer like aqueous cream, that will help.

P: Aque...? (McCarter, 2014, p.132)

The first conversation shows that the actional intent of the physician is to inform the patient about the test results and describe them. In order to inform the patient about the results, such statement as "You are...+ adjective" is used. In order to describe the results, an introductory phrase as "It just means" and an evaluative phrase as "is a little on the low side" are used.

The second dialogue demonstrates such physician's intention as prediction. In order to achieve this, first conditional is used. It is noteworthy that before giving his/own prediction, the specialist denies patient's suspicion about the cause of the disease, namely, poor hygiene.

\section{Role of a Healthcare Provider in a Communicative Event and its Realisation}

This section offers an insight into the abilities of an interlocutor, that is, a healthcare provider, to communicate and his/her role in a communicative act. It also includes an assessment framework which helps to evaluate adequacy of a communicative act, taking into account various factors. 
When it comes to communicative competence, the role of communication participants should be discussed, as the underlying ability of interlocutors to use a target foreign language is one of the most important factors in communication (Rickheit \& Strohner, 2008). According to Savignon (1976), native and nonnative language users have different abilities of exploiting a language. A native speaker "knows not only how to say something but what to say and when to say it", due to the reason that "the linguistic features of an exchange are embedded in a cultural context” (Savignon, 1976, p.4). A non-native speaker has to acquire a set of specific linguistic macro- and microstructures as well as get acquainted with the cultural background of the country and peculiarities of the society where a foreign language is spoken in order to be able to interact fluently (ibid.).

Moving to the discussion of the capabilities of a non-native speaker to communicate in a foreign language, it should be admitted that poor foreign language knowledge is an obstacle to physician-patient communication that may result in hindering effective interaction (Isaacs et al., 2011, Travaline et al., 2005). If a specialist has a low level of foreign language proficiency as well as is unaware of the situational, social and cultural settings of a working place, the flow of conversation can get distorted (Isaac et al., 2011). Consequently, poor communication may be the cause of patient's anxiety (Finlay \& Sarangi, 2006). Moreover, it may become a source of complaints and litigation from patient's side (ibid.). As a result, it makes it hardly possible for a healthcare specialist to provide good quality medical care or treatment.

In the medical settings, conversation participants take different roles. It was established that, regardless of the medical practitioner's language proficiency level, he/she is more empowered in terms of influencing conversation flow in comparison with a patient; it implies that this is the healthcare provider who "controls the topics and their development, deflects or ignores patient topics or contributions that he or she deems irrelevant, provides the amount of medical information that he or she deems appropriate” (Barton, 2005, p.172). This may be achieved with the help of various techniques such as explicit categorisation, for example, "There are three important things that I would like to discuss [...] (Kurtz, Silverman, \& Draper, 2016, p. 47). Thus, a healthcare provider is in charge of the effectiveness of communication, and, consequently, its outcomes.

Interlocutor's knowledge and skills, an ability to use them, psychoemotional factors that surround him/her, interlocutor's environment, as well as his/her actions define if communication is possible at various levels. According to Hymes, the evaluation of the above-stated issues is significant for prediction of the success of communication. This way, it is essential to determine:

1. whether (and to what degree) something is formally possible;

2. whether (and to what degree) something is feasible in virtue of the means of implementation available; 
Pašinska, 2021. Peculiarities of Healthcare Specialists' Communicative Competence in English as a Foreign Language

3. whether (and to what degree) something is appropriate (adequate, happy, successful) in relation to a context in which it is used and evaluated;

4. whether (and to which degree) something is in fact done, actually performed, and what its doing entails. (Hymes, 1972)

The formal possibility refers to the interactant's possession of knowledge of a language system which allows him/her to communicate. In medical settings, successful communication between a healthcare provider and a patient is possible if both of them share a target language and can clearly express themselves in it. For this reason, when a medical student graduates, he/she is expected to have not only the knowledge of the medical field, but also the language of the medical discourse community, which enables him to fulfil his/her duties (Zethsen \& Askehave, 2006). For example, in the context of Latvia, nurses are expected to communicate in at least one foreign language (The Ministry of Education and Science, 2020).

The feasibility in terms of means of implementation, in its turn, is concerned with the "psycholinguistic factors such as memory limitation, perceptual device, effects of properties such as nesting, embedding, branching" caused by the "features of the body and features of material environment as well" (Hymes, 1972, p.285). For example, an interaction between a physician and a patient is possible if a physician is able to interpret patient's body language and comprehend the physiological and psychological factors that caused it. In addition, communication between a healthcare provider and a patient is feasible when it takes place in a medical institution, where the necessary medical equipment can be found and patient's data - accessed.

The question of appropriateness deals with the employment of verbal and body language culturally and socially adequately (ibid.). Since body language differs in various cultures, a healthcare specialist is expected to be aware of basic intercultural differences, which makes him/her prepared for communication with a patient. For example, in American culture, on such formal occasions as communication with healthcare providers, eye contact signals "attentiveness", "respect" and "truthfulness" (Martin \& Chaney, 2012, p.52). From image 1, that is, a screenshot from the American film "The choice" it may be seen that eye contact between a physician and a patient's relative is supported throughout the whole conversation. 


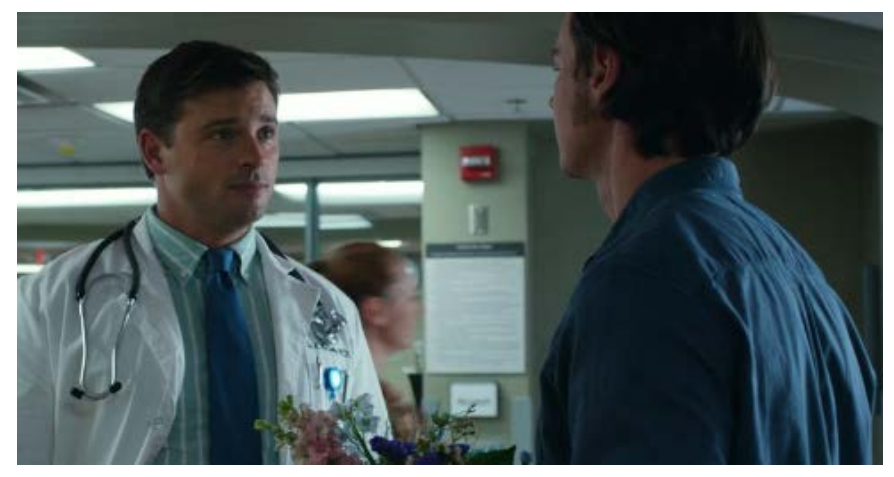

Image 1 Screenshot from the film "The choice"

In the culture of Japan, in its turn, it is not recommended keeping eye contact with a patient, if to adhere to the rules of their culture. It may be interpreted as a rude behaviour. The Japanese try to avoid eye contact $90 \%$ of their time finding it to be improper (Lewis, 2010). They also believe that 'not looking into other person's eyes during a conversation shows respect' to the person with whom they are contacting (Martin \& Chaney, 2012). Image 2, a screenshot from the Japanese film "Our little sister", depicts that in the settings of a hospital the conversation participants avoid a direct eye contact.

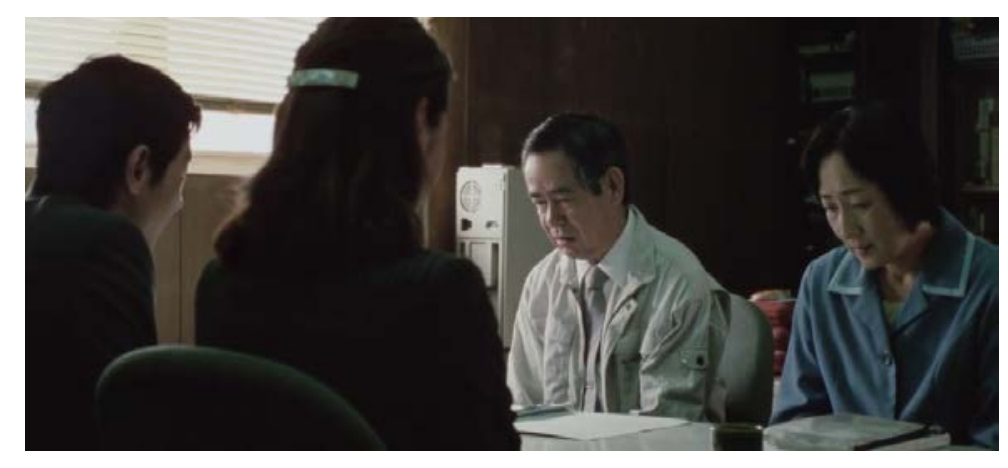

Image 2 Screenshot from the film "Our Little Sister"

The last question of actual performance deals with the accomplishment of a certain communicative task and its effect (Hymes, 1972). In the medical field, the result of a conversation might be the obtainment of consent from a patient or his/her relative to perform a procedure after a detailed explanation of this procedure and its consequences. Another example is a filled in registration form which includes all necessary information for patient's further examination and treatment. 
Pašinska, 2021. Peculiarities of Healthcare Specialists' Communicative Competence in English as a Foreign Language

\section{Conclusions}

This study has aimed at outlining the peculiarities of communicative competence, including its related competences, more specifically, their manifestation in the medical field, that is, medical encounters in English between a healthcare specialist and a patient. The results of the research presented here have revealed that communicative and other competences that refer to the communicative one are essential for medical practitioner's qualification, due to the reason that communication with patients, which often happens in intercultural settings in English, is an indispensable part of medical practitioner's professional life.

It has been discovered that communication never happens in isolation from a situational context, society, culture, intentions and accompanying actions, which implies that communicative competence is interconnected with linguistic, discourse, sociocultural, actional and strategic competences. Thus, communicating in the medical settings, a healthcare provider is expected to take into account situational and sociocultural factors, and adapt to them by choosing appropriate micro- and macrostructures of a target language and appealing to the register typical of the discourse. In addition, a specialist is expected to apply various linguistic strategies and strategic tactics for the achievement of the goals being set.

It has also been established that these are the interaction participant, namely, his/her native language, the level of foreign language proficiency, awareness of the situational and sociocultural aspects of communication that influence the course of a conversation, and determine its efficiency and results. When participating in an encounter, including the medical one, it is essential to evaluate if it is formally possible, feasible, appropriate, as well as to assess a likelihood of an oral task to be performed.

This research has a practical application: the awareness of the importance of communicative competence and related to it linguistic, discourse, sociocultural, actional and strategic competences for a healthcare provider's profession, as well as their peculiarities may serve as the basis for study programme actualisation and teaching material development aimed at specialists' communication skills enhancement.

Despite its exploratory nature, this study offers some insight into healthcare specialists' communicative competence, which is vital for the accomplishment of their professional duties. Therefore, the findings could be treated as useful for further exploration of the issue. 
SOCIETY. INTEGRATION. EDUCATION

Proceedings of the International Scientific Conference. Volume V, May $28^{\text {th }}-29^{\text {th }}$, 2021. 599-614

\section{References}

Barton, E. (2005). Medicine and language. In P. Strazny (Ed.), Encyclopedia of Linguistics (672-675). Abington: Taylor \& Francis Group.

Bryman, A. (2012). Social Research Methods, $4^{\text {th }}$ ed. New York: Oxford University Press.

Celce-Murcia, M. (2007). Rethinking the role of communicative competence in language teaching. In E. Alcyn Soler and M. P. Safont Jorda (Eds.) Intercultural Language Use and Language Learning (41-57). Berlin: Springer.

Celce-Murcia, M., Dörnyei, Z., \& Thurrell, S. (1995). A pedagogical framework for communicative competence: a pedagogically motivated model with content specifications. Issues in Applied Linguistics 6 (2), 5-35.

Chamsi-Pasha, H. \& Albar, M. (2016). Doctor-patient relationship: Islamic perspective. Saudi medical journal, 37, 121-126.

Chomsky, N. (1965). Aspects of the Theory of Syntax. Cambridge, Massachusetts: The M.I.T. Press.

Coelho, E. (2004). Adding English: A Guide to Teaching in Multilingual Classrooms. New York: Holt, Rinehart and Winston.

Finlay, I. G. \& Sarangi. S. (2006). Medical discourse: communication skills and terminally ill patients. In K. Brown (Ed.), Encyclopedia of Language and Linguistics: Volume, $1^{\text {st }}$ vol., $2^{\text {nd }}$ ed. (665-674). London: Elsevier.

Grice, T. (2011). Oxford English for Careers: Nursing 1. Student's Book. Oxford: Oxford University Press.

Gross, P. \& Baumgart D. C. (2006). Sprachkurs Medical English. Stuttgart: Thieme.

Hatch, E. (1992). Discourse and Language Education. Cambridge: Cambridge University Press.

Heritage, J. \& Maynard, D. (Ed.), (2006). Communication in Medical Care: Interaction Between Primary Care Physicians and Patients. Cambridge: Cambridge University Press.

Hymes, D. H. (1972). On Communicative Competence. In J. B. Pride and J. Holmes (Eds.), Sociolinguistics: selected readings (269-293). Harmondsworth: Penguin.

Isaacs, T., Laurier, M., Turner, C. \& Segalowitz, N. (2011). Identifying second language speech tasks and ability levels for successful nurse oral interaction with patients in a linguistic minority setting: an instrument development project. Health Communication, 26, 560-70.

Kurtz, S, Silverman, J. \& Draper, J. (2016). Teaching and Learning Communication Skills in Medicine, $2^{\text {nd }}$ ed. London: Francis \& Taylor Group.

Levetown, M. (2008). Communicating with children and families: from everyday interactions to skill in conveying distressing information. Pediatrics, 121 (5), e1441-e1460.

Lewis, R. D. (2010). When cultures collide: leading across cultures, $3^{\text {rd }}$ ed. Boston: Nicholas Brealey Publishing.

Lloyd, M. \& Bor, R. (2009). Communication skills for medicine, $3^{\text {rd }}$ ed. London: Churchill Livingstone Elsevier.

Martin, J. S. \& Chaney L. H. (2012). Global Business Etiquette: A Guide to International Communication and Customs, $2^{\text {nd }}$ ed. Westport, Conn: Praeger.

McCarter, S. (2014). Oxford English for Careers. Medicine 2. Student's Book. Oxford: Oxford University Press.

McCarter, S. (2013). Oxford English for Careers: Medicine 1. Student's Book. Oxford: Oxford University Press.

Miller A. D, Mishra S. R, Kendall, L., Haldar, S., Pollack, A. H \& Pratt, W. (2016). Partners in care: design considerations for caregivers and patients during a hospital stay. CSCW: Proceedings of the Conference on Computer-Supported Cooperative Work, 754-767. 
Pašinska, 2021. Peculiarities of Healthcare Specialists' Communicative Competence in English as a Foreign Language

Mutha, S., Allen, C. \& Welch, M. (2002). Toward Culturally Competent Care: A Toolbox for Teaching Communication Strategies. San Francisco: Center for the Health Professions, University of California.

Ponomarenko, E., Magirovskaya, O. \& Orlova, S. (2020). Professional discourse in the focus of functional linguistics. In Elena N. Malyuga (Eds.) Functional Approach to Professional Discourse Exploration in Linguistics (1-20). Singapore: Springer.

Rickheit, G. \& Strohner, H. (2008). Handbook of Communication Competence. Berlin: Walter de Gruyter.

Roter, D. \& McNeilis, K. S. (2003). The nature of the therapeutic relationship and the assessment and consequences of its discourse in routine medical visits. In T. Thompson, A. Dorsey, K. Miller, and R. Parrott (Eds.) Handbook of Health Communication (121-140). Mahwah, NJ: Lawrence Erlbaum Associates.

Savignon, S. J. (1972). Communicative Competence: An Experiment in Foreign-Language Teaching. Philadelphia: Center for Curriculum Development.

Savignon, S. J. (1976). Communicative competence: theory and classroom practice. Proceedings of the Central States Conference on the Teaching of Foreign Languages. $23^{\text {rd }}$ April, 1976, Detroit. Retrieved from https://eric.ed.gov/?id=ED135245

The Ministry of Education and Science (2020). Professional standard: Nurse. Retrieved from https://registri.visc.gov.lv/profizglitiba/dokumenti/standarti/2017/PS-144.pdf

Travaline J. M, Ruchinskas R. \& D’Alonzo, G. E. (2005). Patient-physician communication: why and how. The Journal of the American Osteopathic Association, 105 (1), 13-18.

Wodak, R. (2006). Medical discourse: doctor-patient communication. In K. Brown (Ed.), Encyclopedia of Language and Linguistics: Volume, $1^{\text {st }}$ vol., $2^{\text {nd }}$ ed. (665-674). L: Elsevier.

World Health Organisation (2005). Preparing a Health Care Workforce for the $21^{\text {st }}$ Century: The Challenge of Chronic Conditions. Retrieved from https://www.who.int/chp/knowledge/ publications/workforce_report/en/

Yule, G. (2010). The Study of Language, 4th ed. Cambridge University Press: Cambridge.

Zethsen, K. K. \& Askehave, I. (2006). Medical communication: professional lay. In Brown, K. (Eds.) Encyclopedia of Language and Linguistics: 14-volume set, $2^{\text {nd }}$ ed. (644-649). London: Elsevier.

\section{Films}

Our Little Sister (2015). [Film] Directed by: Hirokazu Koreeda. Japan: GAGA Corporation. The Choice (2016). [Film] Directed by: Ross Katz. The USA: Lionstage Moovies. 